Daughaday, W.H. \& Parker, M.L. (1963) Sulfation factor measurement as an aid in the recognition of pituitary dwarfism. J. clin. Endocr. 23, 638.

Daughaday, W.H., Salmon, W.D. \& Alexander, J. (1959) Sulfation factor activity of sera from patients with pituitary disorders. J. clin. Endocr. 19, 743.

FrantZ, A.G. \& RabKIN, M.T. (1965) Effects of oestrogen and sex differences on secretion of human growth hormone. J. clin. Endocr. 25, 1470.

Geller, J. \& LoH, A. (1963) Identification and measurement of growth hormone in extracts of human urine. J. clin. Endocr. 23, 1107.

GiRaRd, J. \& Greenwood, F.C. (1967) The radioimmunoassay of urine for human growth hormone. J. Endocrin. 37, xxxiv.

Glick, S.M., Roth, J., Yalow, R.S. \& Berson, S.A. (1963) Immunoassay of human growth hormone in plasma. Nature (Lond.), 199, 784.

Glick, S.M., Roth, J., Yalow, R.S. \& Berson, S.A. (1965) The regulation of growth hormone secretion. Rec. Prog. Hormone Res. 21, 241.

Greenwood, F.C., Hunter, W.M. \& Klopper, A. (1964) Assay of human growth hormone in pregnancy at parturition and in lactation. Brit. med. J. i, 22.

Hartog, M., GaAfar, M.A. \& Fraser, T.R. (1964a) Effect of corticosteroids on serum growth hormone. Lancet, $\mathbf{i}$, 376.

Hartog, M., GaAfar, M.A., Meisser, B. \& Fraser, T.R. (1964b) Immunoassay of serum growth hormone in acromegalic patients. Brit. med. J. ii, 1229.

Hunter, W.M. \& Greenwood, F.C. (1964) A radioimmunoelectrophoretic assay for human growth hormone. Biochem. J. 91, 43.
Joplin, G.F., OAKley, N.W., Hill, D.W., Kohner, E.M. \& FRASER, T.R. (1967) Diabetic retinopathy, II. Comparison of disease remission induced by various degrees of pituitary ablation by $\mathrm{Y}^{90}$. Diabetologia (In press).

KNOBIL, E. (1966) The pituitary growth hormone: an adventure in physiology. Physiologist, 9, 25.

Lau, K.S., Gottlieb, C.W. \& Herbert, V. (1966) Preliminary report on coated charcoal immunoassay of human chorionic 'growth hormone-prolactin' and growth hormone. Proc. Soc. exp. Biol. (N.Y.), 123, 126.

Merimee, T.J., Burgess, J.A. \& Rabinowitz, D. (1966) Sexdetermined variation in serum insulin and growth hormone response to amino acid stimulation. J. clin. Endocr. 26, 791.

Müller, E.E., Saito, T., Arimura, A. \& Schally, A.V. (1967) Hypoglycaemia, stress and growth hormone release: blockade of growth hormone release by drugs acting on the central nervous system. Endocrinology, 80, 109.

Oakley, N.W., Wright, A.D., Fraser, T.R. \& Haslam, R.M. (1967) Fasting blood-sugar and serum-growthhormone in hypopituitary diabetics. Lancet, i, 523.

Powell, E.D.U., Frantz, A.G., Rabkin, M.T. \& Field, R.A. (1966) Growth hormone in relation to diabetic retinopathy. New Engl. J. Med. 275, 922.

Rosselin, G., Assan, R., Yalow, R.S. \& Berson, S.A. (1966) Separation of antibody-bound and unbound peptide hormones labelled with iodine-131 by talcum powder and precipitated silica. Nature (Lond.), 212, 355.

Roth, J., Glick, S.M., Cuatrecasas, P. \& Hollander, C.S. (1967) Acromegaly and other disorders of growth hormone secretion. Ann. intern. Med. 66, 760.

Touber, J.L. \& MAINGAY, D. (1963) Heterogeneity of human growth hormone. Its influence on a radioimmunoassay of the hormone in serum. Lancet, i, 1403.

Welborn, T.A. \& Fraser, T.R. (1965) The double-antibody immunoassay of insulin. Diabetologia, 1, 211.

\title{
Total fasting in the treatment of obesity
}

\author{
I. C. Gilliland \\ Royal Postgraduate Medical School, and Prince of Wales' \\ General Hospital, London
}

IN AN affluent and labour-saving society energy intake often exceeds output and consequently obesity is the most frequently encountered metabolic disturbance. It is known to be associated with an increased morbidity and mortality rate. As Harrison \& Harden (1966) point out, if this increased mortality rate returns to normal on losing weight (Metropolitan Life Assurance Co., $1962)$ then measures to lose weight must necessarily be of major therapeutic importance. Current methods of sub-caloric diet weight reduction tend to be very unsatisfactory. Stunkard \& McLaren-Hume (1959) showed that out of 100 patients attending an ordinary weight-reduction clinic only two had lost weight after 2 years.

Fasting was described by Folin \& Denis in 1915 as 'a safe, harmless and effective method for reducing the weight of those suffering from obesity', and in the same year Benedict (1915) reviewed many previous examples of lengthy fasting as well as giving detailed observations on his own patient. Bloom (1959) revived this method of absolute starvation and much interest has since been concentrated on it. Bloom's initial periods of fasting were short, but very much longer periods have since been reported by Thomson, Runcie \& Miller (1966) and Harrison \& Harden (1966). We are here recording our experience with forty-six patients whose reducing regime started with a standard absolute fast for 14 days.

\section{Patients}

Any patient with sufficient motivation to seek 
help because of obesity was accepted. Three patients with obesity and diabetes, two with obesity and gout, and one with cardio-pulmonary failure due to the obesity, were urged to adopt this regime. Two who were also urged to this regime were referred by our surgical colleagues prior to operation. There were fourteen male and thirty-two female subjects taking part.

Their ages varied from 16 to 75 years. Initial body weight was a maximum of $140 \mathrm{~kg}(308 \mathrm{lb})$ and a minimum of $67 \mathrm{~kg}(147 \mathrm{lb})$.

The programme consisted of a 14-day period of complete starvation followed by a diet between 600 and 1000 calories. The aim was to reduce weight to $+10 \%$ of the weight at 25 , or alternatively the figure obtained from the Life Insurance Tables of $10 \%$ overweight. The object of a target was to ensure that the patients understood that the starvation period was only the commencement of a continuous programme stretching over many months.

\section{Procedure}

Patients were put on the normal ward diet for the first $24 \mathrm{hr}$ of hospital admission while base-line readings were made. The starvation period then commenced. They were weighed daily each morning after emptying the bladder. Fluid was allowed ad libitum, in some cases distilled, calcium-free water, and in others ordinary tap-water. Black coffee or tea without milk was freely allowed. No attempt was made to replace vitamins or iron over this short period. Patients were not isolated or bed-confined, but were not allowed strenuous exercise. At the conclusion of the 14-day fast period patients were put onto a diet of 600-1000 calories and allowed home except in cases where serious illness had accompanied admission. A few volunteered to stay in hospital a further 14 days while observations continued to be made. Two patients, both with ischaemic heart disease and angina, have asked to undergo a second period of starvation when their home efforts appeared to be too slow. Follow-up appointments were always arranged before the patient left hospital.

\section{Biochemical}

In most patients serial observations were made upon serum and urinary electrolytes, blood urea, uric acid and glucose.

Glucose, bicarbonate and urea were estimated in the routine laboratory by AutoAnalyser. Sodium and potassium were estimated by flame photometer. Uric acid was initially measured manually but the procedure was later automated (Bywaters \& Holloway, 1964).
Eight patients were put on calcium-free distilled water and estimates of their calcium output, serum calcium phosphorus and phosphatase were made serially throughout the fasting period.

\section{Results}

Weight-loss over the 14-day period averaged $7.82 \mathrm{~kg}(17.2 \mathrm{lb})$, ranging from $3.5 \mathrm{~kg}(7.7$ lb) to $14.5 \mathrm{~kg}(31.9 \mathrm{lb})$. All but the most sophisticated patients preferred to record their weight-loss in stones and pounds. After this initial loss of weight there was a sharp gain in weight on resuming feeding of approximately $3 \mathrm{~kg}$ $(6.6 \mathrm{lb})$ in those few patients in which this weight was measured. It appeared that this weight gain was roughly comparable to the initial sharp loss of weight at the commencement of starvation. A graph was constructed to show this phenomenon from one patient's records who remained in the hospital under observation, and this graph was utilized to explain the phenomenon to succeeding patients (Fig. 1). It was hoped that this

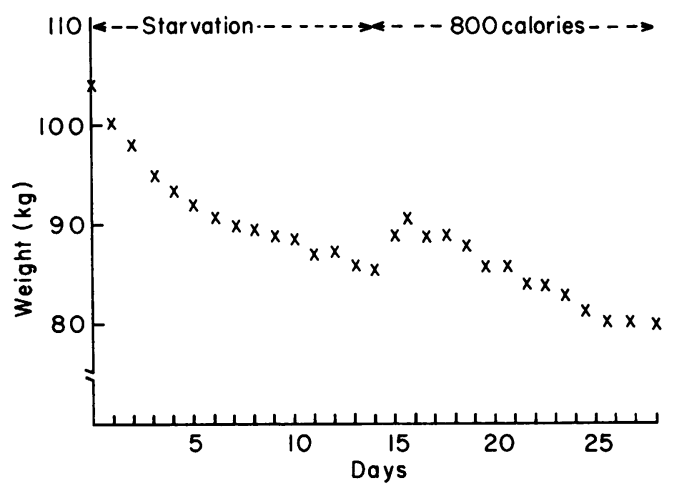

Fig. 1. Weight loss. Miss H.P., age 23.

might help to lessen the disappointment that patients experienced on re-weighing themselves after leaving hospital. Patients were asked not to weigh themselves within the first fortnight, but to come back to hospital and be weighed there. At the end of a fortnight on sub-caloric diet we anticipated their weight being approximately that at which they left hospital.

Short-term results were good. Two patients were not able to complete the course, one through nausea and one simply terminated it at her request. Forty-four completed it with satisfaction. Of these forty-four none experienced complications. Indeed many became slightly euphoric, and this euphoric attitude continued 
into the period of restricted dieting. All these patients were able to adhere to a sub-caloric diet on leaving the hospital and declared themselves fully satisfied on this regime.

Long-term results at 2 years are less satisfactory. Twenty-three $(50 \%)$ have either returned to their initial weight, or failed to follow-up at the clinic. Assuming this failure to follow up to mean a failure to maintain weight loss, this implies that half the patients did not show a long-term benefit from this procedure.

Eleven $(24 \%)$ have continued to lose weight on follow-up and have achieved approximately the target of weight set them. These patients were considered wholly satisfactory. The remainder are erratic in behaviour and have neither been fully satisfactory nor reverted completely to their original state.

\section{Ketonuria}

We observed, as others, that ketonuria commenced on the second day, lasted throughout the period of starvation and abruptly disappeared on the resumption of dieting.

\section{Diabetes}

Our obese diabetic patients developed a similar starvation ketosis. We could not distinguish between this and the ketosis of other obese patients. The fasting level of glucose slowly fell and the glucose tolerance test approached normal after the period of starvation. They have been well controlled without insulin in the poststarvation period.

\section{Bicarbonate}

Plasma bicarbonate concentrations tended to fall in healthy subjects and in the gouty and diabetic. Some of the patients with respiratory troubles did not show much change in bicarbonate level.

\section{Uric acid}

Serum uric acid rose sharply to about the seventh day reaching to levels over $8 \mathrm{mg} / 100 \mathrm{ml}$ in all cases by this time. It fell again on the resumption of dieting. Where serum bicarbonate and uric acid estimations were made on the same sample we have plotted them together in Fig. 2. This clearly demonstrates that there is no direct correlation between bicarbonate and uric acid concentrations. Allopurinal, $100 \mathrm{mg}$ 12-hourly, did not prevent this rise in uric acid in three subjects. Further and more detailed observations are being made on the raised uric acid of starvation and will be the subject of a separate report.

\section{Calcium}

In eight patients in whom calcium-free water was given the level of calcium in the urine remained about $100 \mathrm{mg} /$ day throughout this short period of starvation. There was no change in serum calcium phosphorus and phosphatase.

\section{Gout}

The patients with gout were started on probenecid the week before the starvation period and this was continued throughout. Their uric acid fluctuations will be the subject of a separate report, but no clinical gout arose in this time.

\section{Cardio-pulmonary}

One patient admitted in severe cardiopulmonary respiratory failure was able to walk slowly without breathlessness by the end of her period of starvation.

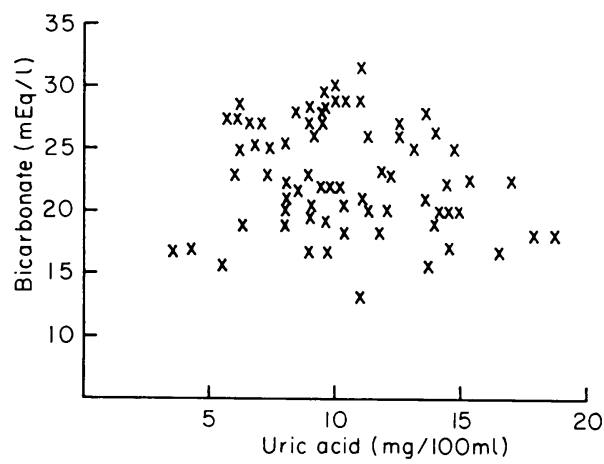

FIG. 2. Starvation for 14 days. Uric acid and bicarbonate simultaneous measurements.

\section{Discussion}

From Biblical times fasting has been recognized as compatible with life, and periods of fasting are often enjoined in religious observances. A feeling of well-being is certainly engendered in this way and may amount to euphoria. We did not encounter complaints of hunger after the first day. We did not meet anorexia. Our experience would agree with that of Silverstone, Stark \& Buckle (1966) that there is an initial increase in hunger which soon disappears and anorexia was not a feature after this.

At the end of the starvation period all patients were perfectly satisfied with their sub-caloric diet although many of them had previously attempted similar diets without success. The sudden weight gain on ceasing starvation is disappointing to many patients. Blondheim, Kaufmann \& Stein (1965) doubted the value of starvation because 
of this subsequent weight gain. However, we agree with Bloom (1959) that the alterations in the subjective response to the sub-caloric diet is probably the main gain of this regime. It demonstrates to patients that dietary measures can indeed cause a weight loss and they are able to accept this after their personal experience.

We encountered no complications in this relatively short period of starvation. Severe complications have occurred after longer periods of starvation; Drenick et al. (1964) report orthostatic hypotension and gouty arthritis; Drenick, Joven \& Swendseid (1966) Wernicke's encephalopathy ; and Cubberley, Polster \& Schulman (1965) a fatal lactic acidosis in a diabetic.

Exceptionally long periods of starvation without serious complication have been reported by Harrison \& Harden (1966) and Thomson et al. (1966). In this latter series intestinal villous atrophy was observed, though the ultimate fate of this lesion is not yet known. We did not attempt long periods as a routine because these patients require to be kept under hospital observation it is not always practical to have beds occupied for such a length of time.

Our experience bears out that of many others that starvation is easy to carry out, relatively safe in hospital, and the immediate benefit is considerable.

Attempts to assess the long-term benefits are more difficult. Of the $50 \%$ who have been regarded as failures, some occurred in the early days before we appreciated the devastating effect on morale of the weight gain that follows the starvation period, even on a low calorie diet. Since we prepared the patients for this phenomenon there has been less initial fall-out. Of the $24 \%$ who have achieved satisfactory results many are those to whom the regime has been conspicuously valuable. One patient with cardiopulmonary failure requiring artificial respiration for the first $48 \mathrm{hr}$ in hospital has lost $14.4 \mathrm{~kg}$ in weight and is already leading an ordinary life. One embarrassed obese adolescent is now a normal young woman. Three diabetics, one previously on insulin, are now excellently controlled on diet only, confirming the observation made by Drenick et al. (1964). Two gouty subjects, with the addition of probenecid, have been free from harassing attacks of arthropathy. We would certainly agree with Cristofori \& Duncan (1964) that gout is no contra-indication to the total fasting regime. None the less, we would think that continued hyperuracaemia must be a certain hazard and measures should be sought to obviate this. Two patients referred by the surgeons have proceeded to operation after satisfactory loss. One has subsequently regained some weight. The remaining two obese subjects are indistinguishable from the majority who failed to maintain the course.

\section{References}

Benedict, F.G. (1915) $\mathrm{A}^{-}$study of prolonged fastings. Publ. Carnegie Inst. 203, pp. 27, 42, 182.

Blondheim, S.H., Kaufmann, N.A. \& Stein, M. (1965) Comparison of fasting and 800-1000-calorie diet in treatment of obesity. Lancet, i, 250.

Bloom, W.L. (1959) Fasting as an introduction to the treatment of obesity. Metabolism, 8, 214.

Bywaters, E.G.L. \& Holloway, V.P. (1964) Measurement of serum uric acid in Great Britain in 1963. Ann. rheum. Dis. 23, 236.

Cristofori, F.C. \& DunCAN, G.G. (1964) Uric acid excretion in obese subjects during periods of total fasting. Metabolism, 13, 303.

Cubberley, P.T., Polster, S.A. \& Schulman, C.L. (1965) Lactic acidosis and death after the treatment of obesity by fasting. New Engl. J. Med. 272, 628.

Drenick, E.J., Joven, C.B. \& Swendseid, M.E. (1966) Occurrence of acute Wernicke's encephalopathy during prolonged starvation for the treatment of obesity. New Engl. J. Med. 274, 937.

Drenick, E.J., Swenseid, M.E., Bland, W.H. \& Tuttle, S.G. (1964) Prolonged starvation as treatment for severe obesity. J. Amer. med. Ass. 187, 100.

Folin, O. \& DENIS, W. (1915) On starvation and obesity, with special reference to acidosis. J. biol. Chem. 21, 183.

HARRISON, M.T. \& HARDEN, R.MCG. (1966) The long-term values of fasting in the treatment of obesity. Lancet, ii, 1340.

Metropolitan Life Assurance Co. (1962) Statistical Bulletin, 43, 1.

Silverstone, J.T., Stark, J.E. \& Buckle, R.M. (1966) Hunger during total starvation. Lancet, i, 1343.

Stunkard, A. \& MCLAREN-Hume, M. (1959) The results of treatment for obesity. Arch. intern. Med. 103, 79.

Thomson, T.J., RUNCIE, J. \& MilleR, V. (1966) Treatment of obesity by total fasting for up to 249 days. Lancet, ii, 992. 